\title{
A Critical Analysis of the Utility and Compatibility of Motivation Theories in Psychiatric Treatment
}

Article in Current Psychiatry Reviews · November 2011

DOI: $10.2174 / 157340011797928204$

CITATIONS

9

4 authors:

Eline C Jochems

GGz Breburg

17 PUBLICATIONS 77 CITATIONS

SEE PROFILE

(श)

Arno van Dam

Tilburg University

142 PUBLICATIONS 373 CITATIONS

SEE PROFILE

Some of the authors of this publication are also working on these related projects:

Project Longterm mental patiënts in Amsterdam (LZA-studie Amsterdam) View project

Project Emergency Psychiatry View project
READS

407

Cornelis L Mulder

Erasmus MC

273 PUBLICATIONS 4,022 CITATIONS

SEE PROFILE

Hugo J Duivenvoorden

Erasmus MC

274 PUBLICATIONS 8,971 CITATIONS

SEE PROFILE 


\title{
A Critical Analysis of the Utility and Compatibility of Motivation Theories in Psychiatric Treatment
}

\author{
Eline Carmen Jochems*, ${ }^{*}$, Cornelis Lambert Mulder, ${ }^{\mathrm{a}, \mathrm{b}}$, Arno van Dam ${ }^{\mathrm{c}}$ and \\ Hugo Joseph Duivenvoorden ${ }^{\text {d }}$
}

\begin{abstract}
${ }^{a}$ O3 Research Centre, Department of Psychiatry, Erasmus Medical Center, Post Office Box 2040, 3000 CA Rotterdam, The Netherlands; ${ }^{b}$ Bavo-Europoort, Prins Constantijnweg 48-54, 3066 TA Rotterdam, The Netherlands; ${ }^{c} G G Z$ Westelijk Noord Brabant, Post Office Box 371, 4600 AJ Bergen op Zoom. The Netherlands; ${ }^{d} 2 e$ De Carpentierstraat 232, 2595 HN, The Hague, The Netherlands
\end{abstract}

\begin{abstract}
The TransTheoretical Model (TTM), Self-Determination Theory (SDT), and the Integral Model of Treatment Motivation (IM) provide distinct but not incompatible conceptualisations of motivation. We discuss the utility of these theories as a basis for the improvement of psychiatric treatment engagement and treatment outcomes in patients with severe mental illness. It appears that all three theories have gained support for their predictions of outcomes in patients with severe mental illness, but important questions remain unanswered, such as which of these theories provides the best prediction of treatment engagement and treatment outcomes. We explain how these three theories could complete each other, based on their strong and unique assets. It is imperative that the theories are empirically tested and compared to confirm their utility, and to this end we propose several important research questions that should be addressed in future research. Theory comparisons can advance what is currently known about intrapersonal changes and interpersonal differences in treatment engagement and outcomes in severely mentally ill patients.
\end{abstract}

Keywords: Motivation - self-determination - transtheoretical - theory - treatment.

\section{INTRODUCTION}

Although numerous theories of motivation and health behaviour exist today, it has been noted by several authors that real innovations and advances in understanding health behaviour have been quite modest $[1,2]$. One of the contributing factors to this lack of advancement in health behaviour theory is said to be that theories are seldom compared with each other in order to determine whether one theory offers a superior explanation of health outcomes than another theory [1-3]. Noar and Zimmerman [1] have further argued that this absence of empirical comparisons between different models, induces fragmented rather than accumulative knowledge regarding the prediction of (health) behaviour. The importance of empirically comparing theories is evident from the fact that we cannot truly know which theories are most accurate in explaining or predicting health behaviour if we do not test this. Clinicians faced with decision making regarding the optimal interventions should be able to rely on theory comparison studies that point out which theories (and accompanying intervention strategies) are best for which patients in which circumstances. We also agree with Noar and Zimmerman [1] that: "The fact that theories have so many similar constructs demands that we (1) try and discover what the best conceptualization of those constructs is, and (2) compare theories to discover how these constructs combine and result in the enactment of health behaviour" (p.282).

*Address correspondence to this author at the Erasmus MC, Department of Psychiatry, Post Office Box 2040, 3000 CA Rotterdam, The Netherlands; Tel: +31 107030146 ; Fax. +31 107033217 ;

E-mail: e.jochems@erasmusmc.nl
The current article aims to provide an overview of three leading theories of motivation and conceptually relates these theories to each other in order to understand their common and unique contributions to the motivation concept. Also, the strengths and limitations of the theories are discussed in light of empirical evidence that these theories have gathered in their prediction and explanation of treatment engagement in patients with (severe) mental illness. This specific context was chosen since patients with severe mental illness (SMI) are generally considered problematic with regard to motivational issues and show high rates of drop-out and attrition from psychiatric treatment [4], which in turn has been shown to deteriorate treatment outcomes [5-7]. The current article serves to raise important research questions and critical thought with which we expect to stimulate research in testing and comparing these theories. First, we will explain how we arrived at the choice of these three specific theories before discussing the theories and how they relate to each other.

\section{THREE MOTIVATION THEORIES}

One of the most influential models of motivation and change, widely used in psychiatric treatment facilities and particularly in the treatment of addiction, is the Transtheoretical model (TTM) developed by Prochaska and DiClemente [8]. TTM has also been called the stages of change model, and is typically regarded as a model for motivation for change, as the motivation to engage in behaviour change increases with each progressive stage [9-10]. The TTM has frequently been used as a basis for the development of health behaviour interventions, especially in the field of addictions [11]. A fundamental assumption in TTM (or any stage model) is that matching interventions to specific stages will 
increase the likelihood that change will occur, as opposed to mismatching or not matching to stages. However, the TTM has been the subject of several conceptual and empirical critiques [9, 12-14]. Interestingly, Drieschner et al. [9] have developed their own motivational model in response to the TTM, as these authors have criticised TTM (among other things) for its limited coverage of motivational factors. The model developed by Drieschner et al. [9] is called the Integral Model of Treatment Motivation (IM) and revolves around six so-called internal determinants that predict the level of motivation to engage in treatment. The IM has a strong focus on individual beliefs, subjective norms and selfefficacy as the proximal predictors of motivation, and the level of motivation would be predictive of subsequent behaviour (e.g. taking medication). The TTM and IM differ from each other, in that the TTM is a stage model while the IM is a continuous model, according to the typical classification by Weinstein, Rothman and Sutton [15]. Stage models assume that behaviour change takes place in discrete stages and that there is a different equation for every stage that predicts progression to the next stage. Hence, interventions based on stage models include different interventions for people in different stages. Continuous models on the other hand, focus on predictors (such as attitudes or motivation) of the patient's decision to perform certain health behaviours. Continuous models combine these predictors in a - often linear prediction equation that places individuals along a continuum of behaviour likelihood. If one scores higher on either predictor in the equation then the likelihood of behaviour or behaviour change is also increased. The question now rises, which theories - stage or continuous - are most valuable in terms of their explanatory and predictive power regarding treatment engagement and treatment outcomes in patients with (severe) mental illness. The current article will discuss the strengths and limitations of the TTM and IM as prototypical examples of these theory types, to see what contributions they have made to the prediction and explanation of treatment engagement and outcomes in patients with SMI.

Although the TTM and IM differ from each other with respect to the type of framework they are composed of, they appear to have in common that the focus is upon predicting the level of motivation. That is, both models employ a quantitative motivation concept where the motivation that an individual may hold can range from a low level/stage to higher levels or stages. Contrasting such a quantitative viewpoint would be a qualitative viewpoint, where motivation is not so much characterised by its level but by its underlying reasons for performing certain behaviour, or to put it in other words, by a type of motivation. One such theory is Self Determination Theory (SDT) [16-17], a theory that has gained much interest in the literature in the last two decades. SDT postulates different types of motivation, where a central distinction is made between autonomous (i.e. self-determined) motivation and controlled (i.e. externally determined) motivation. Specifically, SDT predicts that autonomous motivation leads to a higher quality of treatment engagement (that is, self-determined treatment engagement) and as a consequence, to a better maintenance of healthy behaviour and more well-being [18]. Furthermore, controlled motivation would be related to a poorer quality of treatment engagement and as a consequence, to poorer maintenance and well-being
[18]. It should be noted however, that although SDT is primarily concerned with the quality of motivation, it is also concerned with the quantification of motivation across the self-determination continuum. Amotivation stands at one end of the self-determination continuum, characterised by the lowest intentions for action, whereas motivation stands at the other end of the continuum, characterised by clear intentions for action, whether they are extrinsic or intrinsic. The addition of SDT as a theory to compare to TTM and IM leads to a second question concerning whether the level of motivation or the type of motivation (or a combination of these) is most important for the prediction of treatment engagement and clinical outcomes. This is another issue that will be addressed in the current article.

Thus, we have now arrived at the selection of the following three theories for our discussion: the TransTheoretical Model [8], the Integral Model of treatment motivation [9] and Self-Determination Theory [17]. These models, their definitions and measurements of the motivation concept and the way in which they predict treatment engagement and treatment outcomes will be described.

\subsection{Transtheoretical Model (TTM)}

TTM describes how individuals pass along five stages towards behaviour change $[8,11,19-20]$. These stages are known as precontemplation, contemplation, preparation, action and maintenance. Precontemplation is the stage at which the individual has no intention to change his behaviour in the foreseeable future, usually defined as the next 6 months [20]. In this stage, patients are unaware of their problems or avoid reading or thinking about their problems. They are therefore considered unmotivated to change at this stage. Contemplation is the stage in which the individual is aware that a problem exists and is seriously thinking about overcoming it over the next six months, but has not yet made a commitment to take action [20]. An important aspect of the contemplation stage is the weighing of the pros and cons of the problem and the solution to the problem. Moving on to the preparation stage, individuals in this stage intend to take action in the next month [20]. Then, in the action stage, the individual modifies his behaviour, experiences, or environment in order to overcome his problems in the preceding six months. Maintenance is regarded as the stage in which the individual works to prevent relapse and consolidate the gains attained during action [20]. Maintenance is considered a continuation of change that extends from six months to an indeterminate period (although estimated to about five years) past the initial action [20]. Interestingly, within each of the five different stages specific problems may occur, depending on specific situations and disorders. For example, patients who suffer from schizophrenia often have impaired insight into their illness [21] which might prevent them from progressing from precontemplation towards the contemplation stage. Figure 1 shows the stages of change and their relations with other constructs in TTM.

According to TTM, individuals progress through the stages sequentially, but relapsing and recycling through the stages is common [11]. Figure 1 shows two possible relapse moments between the stages. Due to the explicit notion of relapsing and recycling, it has been argued that TTM has 


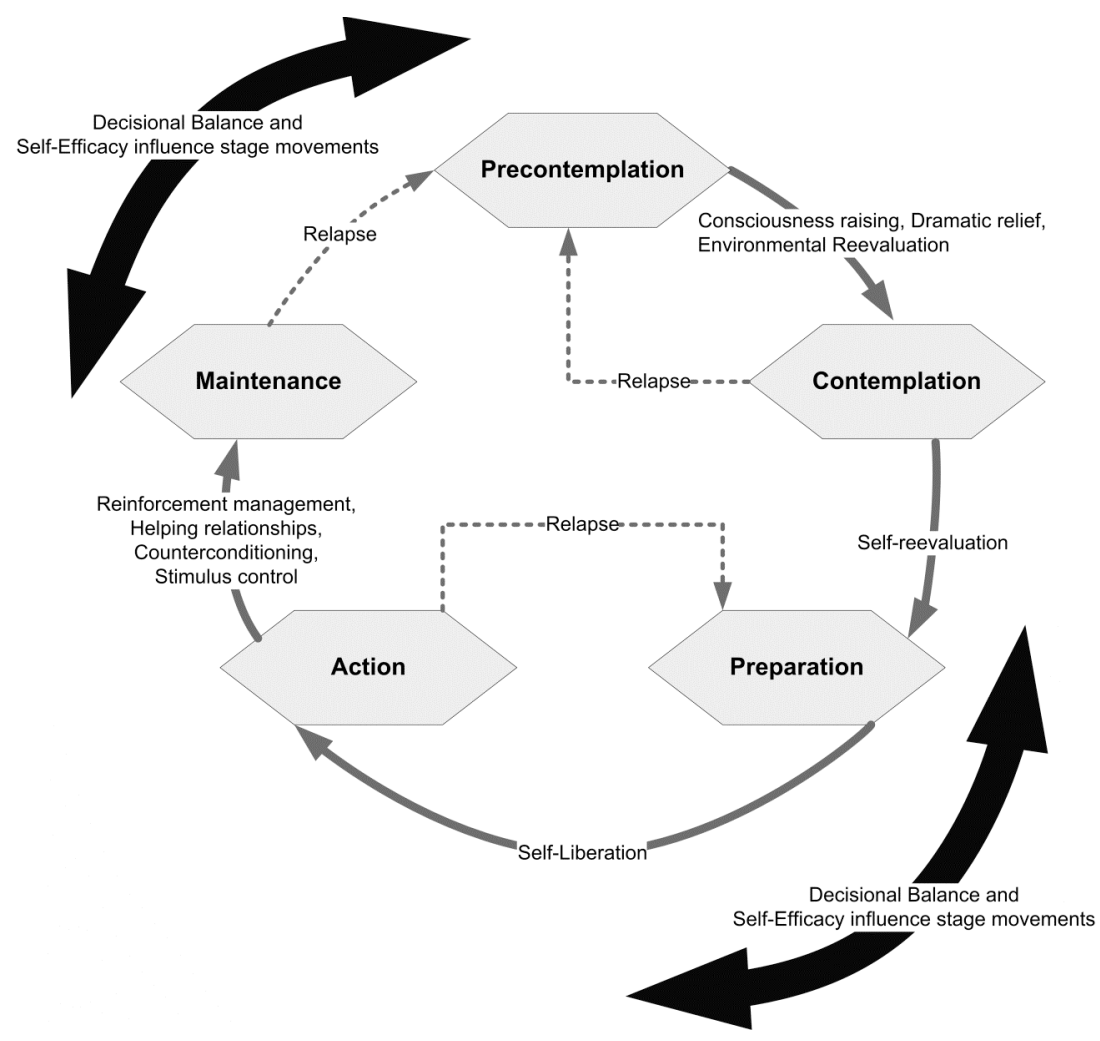

Fig. (1). TransTheoretical Model, adapted from Prochaska et al. [11] and Prochaska [20].

been successful in promoting a less pejorative view of people who are not ready for change and that the model has heuristic appeal [13]. TTM describes how fourteen constructs, including two decisional balance constructs, two selfefficacy constructs and ten processes of change determine transitions between the stages $[19,22]$. These ten processes of change can be divided into two categories: experiential processes and behavioural processes. Experiential processes include activities related to thinking about the health behaviour change (e.g. consciousness raising, self-re-evaluation, environmental re-evaluation), while behavioural processes are categories of behaviours that are supposed to be helpful for the achievement of the behaviour change (e.g. stimulus control, reinforcement management) [8]. Prochaska et al. [23] have argued that the ten processes of change are "like independent variables that people need to apply to move from stage to stage" (p.63). However, several problems with both the stages of change and processes of change have been noted [24-26], as we shall discuss in the following.

\subsubsection{Definition and Measurement of the Constructs in the TTM}

A basic and substantial problem with the TTM is the way in which the stages of change are defined and measured. Several measures have been developed to assess the stages of change, including categorical stage assignments based on stage algorithms [11] and continuous measures (e.g. the Readiness to Change Questionnaire (RCQ) [27] the University of Rhode Island Change and Assessment (URICA) Scale [28], Motivation for Treatment Questionnaire [29]). Continuous measures have the advantage that they have been shown to have good agreement between different scales and between clients and clinicians [30], but a disadvantage is that they do not provide a representation of all five stages of the model. For example, the RCQ only distinguishes between the precontemplation, contemplation and action stages, while the URICA incorporates these three and the maintenance stage but not the preparation stage. The URICA has been modified into the URICA-M to suit the needs of people with SMI [31]. The URICA-M contains the same four subscales as the URICA, but includes reading items aloud to accommodate individuals who cannot read, modified language to make it simpler and includes only 24 items [31]. Overall, in a sample of patients with SMI and co-occurring substance use all subscales of the URICA-M showed good reliability (i.e. $\alpha=.72$ or higher), except for the maintenance subscale that showed moderate reliability $(\alpha=.67$ to $\alpha=.70)$. When reanalysed within diagnostic and substance use groups, the results suggested that the URICA-M was more reliable for schizophrenia and substance dependent groups than for nonpsychotic affective groups and substance remitted groups [31]. It appears that, compared to other TTM measures (e.g. of the processes of change, self-efficacy and decisional balance) that were also studied by Nidecker et al. [31], the URICA-M showed inferior reliability, especially for patients with affective disorders and those in remission. Furthermore, a disadvantage that remains with the URICA-M (and other continuous measures of the stages) is that participants can endorse items representing at least two different, sometimes nonadjacent stages. If participants turn out to be in multiple stages at the same time however, the validity of discrete stages is called into question $[13,26]$. 
Where most continuous measures for the stages of change do not represent all five stages of the model, algorithms enable placing individuals in either of five stages and have been used extensively in diverse populations and research areas $[11,22,30]$. The algorithm approach involves a series of questions that ask about attempts and intentions to change behaviour within certain time frames that correspond to a particular stage. A disadvantage of most of the staging algorithms, as pointed out by Sutton [24], is that the time periods are arbitrary and in some cases, the staging algorithms are logically unsound. Using different time periods would lead to a different stage allocation and a different stage attribution [24]. Furthermore, studies have shown low concordance between these different stage measures [24] and in different studies, there have been inconsistencies in the definitions of the stages [25]. Obviously, the practical utility of the TTM is called into question if the stages cannot be assessed readily. Some authors have even argued that the problems with the TTM are so serious that the theory should be discarded entirely [12] or that the model should not be regarded as a descriptive model but as a prescriptive model a model of ideal change [26]. However, supporters of the model favour its practical utility and argue that the shortcomings of the TTM still pale in comparison to other models that have traditionally excluded unmotivated individuals, whereas TTM has been dedicated to specifically also include unmotivated individuals who need the most help [32].

Furthermore, the TTM does not appear to differentiate between the determinants of motivation and the motivation concept itself, for which it has been criticised [9]. Drieschner et al. [9] have interpreted the stages of change within TTM not as temporally ordered levels of a single dimension (motivation to engage in the process of behaviour change) but instead argue that the stages conceptually encompass two underlying components. The first consists of the cognitive determinants of motivation to change and the second consists of behaviour that results from a certain level of treatment motivation. In his criticism upon the TTM, Sutton [24] has also noted this, and he states that the stages of precontemplation, contemplation and preparation may be seen as the "planned time to action" (p.176). Looking at the TTM this way, the level of motivation to engage in treatment then rises as one moves from the precontemplation stage to the preparation stage, and leads to actual behaviour changes from the action stage onwards.

Other constructs of the TTM, such as the decisional balance constructs and self-efficacy constructs, are typically measured with Likert scales that ask patients about the relative importance given to pros and cons when making the decision to engage in the relevant health behaviour and how they judge their own capacity to perform certain behaviour. A decisional balance scale has also been constructed [33]. For the assessment of the processes of change, the Processes of Change Inventory was developed for individuals trying to quit smoking [34]. A revised processes of change inventory (a shortened version of the original 40-item scale) has been validated in a sample of SMI patients with co-occurring substance disorder [31]. However, the processes of change remain the least studied dimension of the TTM. This is rather strange, since the processes of change represent a core as- sumption of TTM: that movement between stages is predicted by the use of the processes of change. Besides the little empirical attention that the processes of change have been given, there are other problems. For example, some of the processes seem more like procedures than processes (e.g. stimulus control) [25] and Dunlap [35] has noted that although TTM establishes the processes of change as important variables that facilitate stage movement, it does not clarify how the processes are initiated or once activated, how they can be stimulated further.

\subsubsection{Prediction of Treatment Engagement and Outcomes}

The different stages of change are hypothesised to predict treatment engagement, dropout, efficacy and long-term maintenance of behaviour changes [19, 36]. More specifically, the amount of progress that patients make following treatment is predicted to be a function of their pretreatment stage of change [11], where patients in lower stages (i.e. precontemplation and contemplation) would make least progress and show higher rates of dropout. Additionally, the processes of change would predict transitions between stages, where the experiental processes should be employed in the early stages to progress to higher stages, and behavioural processes should be endorsed in the action and maintenance stages of change.

It has been noted that the available longitudinal evidence for TTM's prediction of change is mixed at best [13, 25]. Studies have shown inconsistencies as to which stage predicts drop-out or behaviour change. In a comprehensive review of the stages of change model (not the entire TTM), Littell and Girvin [13] concluded that there was "scant evidence of sequential movement through discrete stages in studies of specific problem behaviours, such as smoking and substance abuse" (p.223). On the other hand, it has been noted by Hutchison, Breckon and Johnston [37] that "the majority of interventions reported to be based on the TTM fail to accurately represent all dimensions of the model. Therefore, until interventions are developed to accurately represent the TTM, the efficacy of these approaches and the appropriateness of the underpinning theoretical model cannot be determined" (p.829). Furthermore, few prospective studies have been conducted to investigate the TTM constructs in patients with severe mental illness. In a study by Rogers et al. [38] it was examined how baseline stages of change scores were prospectively related to retention in a vocational intervention with patients with SMI. At three months, none of the stages were significantly related to retention, and at six months only the contemplation stage was a significant predictor of better retention while at nine months again none of the stages had predictive value [38]. A study by Pantalon and Swanson [39] showed that, contrary to TTM's predictions, dually diagnosed patients in lower stages of change (measured with the URICA) had greater treatment adherence one month after discharge from hospital than patients in higher stages, in that they attended a greater proportion of therapy groups and clinical appointments. Also, patients in lower stages were more likely to attend all of their scheduled appointments than those in higher stages [39]. Crosssectional studies have also shown inconsistent findings with respect to the validity and utility of the TTM stages of change (e.g., [40-43]). Since it has been shown that the TTM 
constructs can be reliably measured in patients with SMI (and co-occuring substance use disorders) [31, 44-45], researchers should now aim to (prospectively) investigate the utility and validity of TTM in patients with SMI.

\subsubsection{Intervention Strategies and Evidence for these Strategies}

Being a stage model, the TTM implies that interventions should be matched to the stage a patient is in. Project MATCH (Matching Alcoholism Treatment to Client Heterogeneity) was a large multisite clinical trial designed to test the matching hypothesis [46]. One of the three treatment arms in this trial, called Motivational Enhancement Therapy, was grounded in the TTM [47]. Of the 16 hypotheses tested in Project MATCH, only one hypothesis was statistically significant: that clients with few psychiatric symptoms would respond better to Twelve-Step facilitation than Cognitive Behavioural Coping Skills Therapy [48]. These negative findings leave us to wonder whether matching patients to stage-specific interventions is worth the effort. However, in a re-examination of the motivation matching hypothesis support was found for the matching hypothesis in the outpatient sample, where individuals with lower baseline motivation had better outcomes if assigned to Motivational Enhancement Therapy compared to those in Cognitive Behavioural Coping Skills Therapy [49]. Overall, evidence for the matching hypothesis and prospective power of TTM is mixed [14, 50-51] and it is still unclear how the matching hypothesis applies to patients with SMI. Furthermore, regarding the use of the TTM in clinical practice, it has been noted by Patterson, Wolf \& Buckingham [52] that: "working with the stages of change seems to require the dedicated attention to that central, one and only, specifically identified problem. (...) The individual and therapist then, have one problem and five different stages to monitor. The multiple challenged clients however, could have up to five equally serious problems to address (i.e. housing, employment, alcohol or drug use, medical conditions, and criminal justice). This would require monitoring five co-evolving problems with five different TTM stages" (p.54). This would be almost impossible to achieve, since the therapist would then have to keep track of five problems and five stages per problem, resulting in 25 possible interventions. It would thus seem that stage-based interventions are less suited for individuals with SMI - a population that almost by definition faces multiple problems. As Littell and Girvin [13] have noted: "Stage-matched interventions seem premature and ill advised. A more realistic approach is taken by Miller and Tonigan (1996), who provided clients with feedback on their SOCRATES scores as a starting point for discussion about their motivation for change" (p. 255).

\subsection{Integral Model of Treatment Motivation (IM)}

The Integral model of treatment motivation (IM) was developed by Drieschner et al. [9] in an attempt to disentangle the determining factors and behavioural consequences of the concept of treatment motivation. The IM defines treatment motivation as "the patient's motivation to engage in their treatment (MET)" ([9], p. 1130). According to the authors, the proximal predictors of the level of MET are six cognitive and emotional factors, called internal determinants of MET. The IM and related concepts is shown in Figure 2. The six internal determinants include problem recognition, level of suffering, perceived external pressure, perceived costs of treatment, perceived suitability of treatment, and outcome expectancy [9]. It is indeed plausible that a distressed patient who recognises his problems, has a high level of perceived legal pressure, combined with optimism about the effect of treatment will have a higher level of MET than a patient with lower levels on these factors. According to IM, the internal determinants mediate the influence of external factors (such as the type of treatment and demographic features) on MET. As the internal determinants are expected to determine the MET, MET in turn would determine the level of treatment engagement. However, the authors argue that this association is not perfect, since patients may lack the cognitive or neuropsychological capacity to do what the treatment requires [9]. Finally, treatment engagement would determine treatment outcome, along with other factors (i.e. external determinants) such as the treatment effectiveness and the persistence of the patients' problems [9].

The IM seems psychologically plausible in that it leaves room for external factors to influence the relation between MET and TE. Indeed, studies have shown that the association between motivation and behaviour is imperfect [54-55]. The authors of IM themselves found that self-reported MET by patients explained 32 percent of the variance of subsequent therapist-rated treatment engagement [56]. Although this percentage compares favourably to values found in other fields of research, it still leaves a large percentage of the variance in treatment engagement to be explained by other factors. The IM is not clear about which exact factors - apart from cognitive functioning - are needed to 'bridge the gap' between MET and TE. It could be an improvement on IM to add intermediary factors between the level of motivation and the actual treatment engagement. Although including such factors will not increase the size of the effect of motivation upon behaviour, it will generally improve the prediction of the behaviour [55] and thus create opportunities to beneficially influence the pathway to behaviour change and maintenance.

\subsubsection{Definition and Measurement of the Constructs in the IM}

Two instruments have been developed to specifically measure the constructs in the IM: the Treatment Motivation Scales for Forensic Outpatient Treatment (TMS-F) to measure the internal determinants and the level of motivation, and the Treatment Engagement Rating Scale (TER). The patient population in which the theory and its measures were tested consisted of individuals with psychiatric and personality problems being treated in a correctional outpatient treatment facility. In several studies with this population, the measurement instruments were found to be reliable and valid [5658]. Although the sample in which the instruments were validated was a heterogeneous one (e.g. $70 \%$ had a axis I DSM-IV diagnosis of which $8 \%$ had a psychotic disorder, and $80 \%$ has substantial characteristics of personality disorders) it remains to be determined whether the TMS-f and TER are also reliable and valid instruments for use in samples of patients with SMI, not necessarily being offenders. 


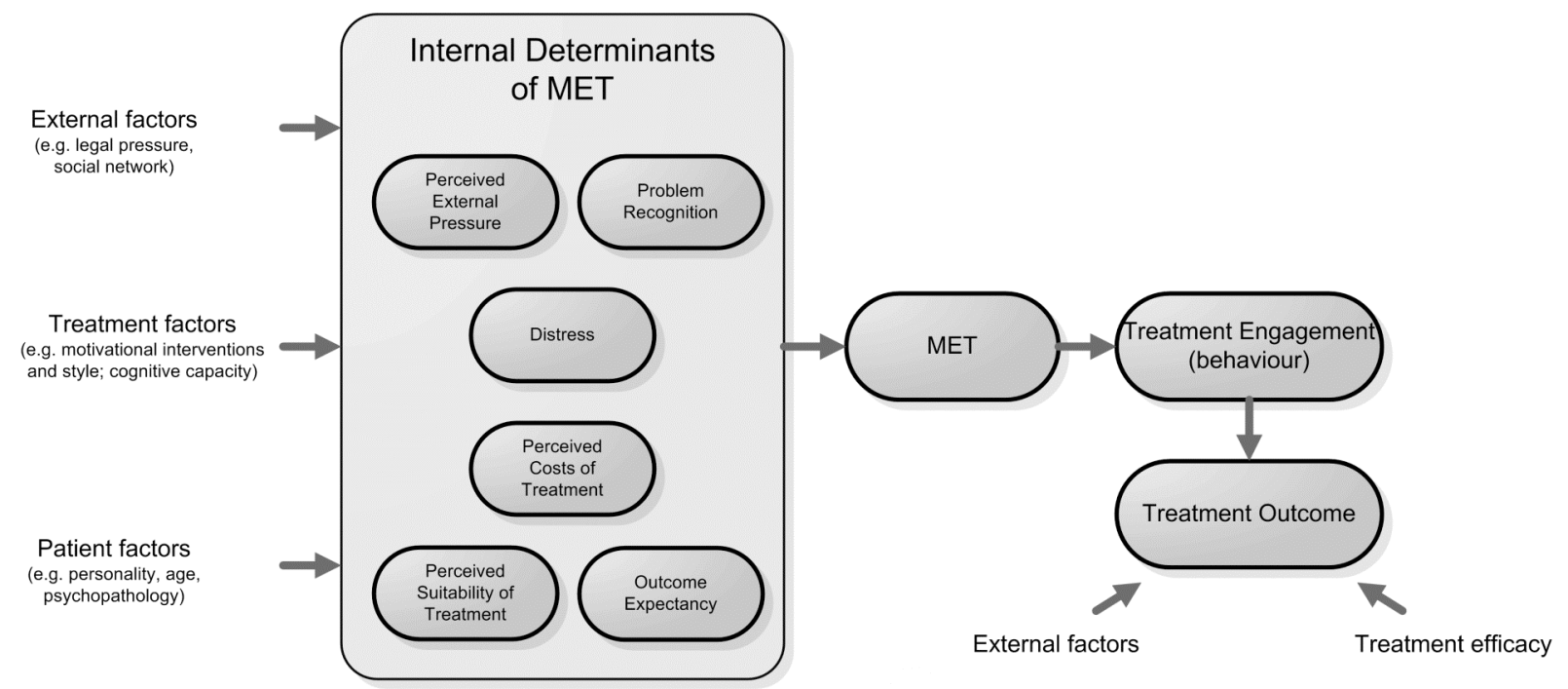

Fig. (2). The Integral Model of treatment motivation and related concepts, adapted from Drieschner et al. [53].

\subsubsection{Prediction of Treatment Engagement and Outcomes}

In the IM, motivation is regarded as the outcome of the combined effects of the internal determinants and it can therefore vary in amount, depending on the values of the internal determinants. According to IM, a higher motivation for treatment induces higher treatment engagement and, as a result, a better treatment outcome. In several studies in forensic psychiatric outpatient centres, Drieschner et al. [5658] have generally found support for the theory that the internal determinants predict the MET which in turn predicts treatment engagement. Outcome expectancy was found to be the best predictor of MET and also predicts engagement in an important degree, albeit indirectly [56]. Furthermore, treatment engagement was found to predict treatment completion and treatment outcome [53]. These findings seem to support the predictions of the Integral Model of the relations between the internal determinants, MET, treatment engagement and treatment outcome. However, there were also some findings that were not in line with IM. For example, treatment engagement was best predicted by the MET scale and by the subscale of Perception of the Suitability of the Treatment, while subscales for Distress and the Perceived Legal Pressure were found virtually unrelated to MET and treatment engagement [56]. Also, the perceived suitability of the treatment was found to predict the treatment engagement directly, beyond the mediated effect of MET. These findings indicate that the patient's appraisal of the treatment is most important for treatment motivation and treatment engagement, while problem recognition, distress and perceived legal pressure are not so much. Actually, as we shall see later on, these findings seem to fall in line with SDT's postulation that when an individual reports motives that are more internalised (such as perceiving the treatment as suitable) this is more predictive of treatment engagement than external motives (such as legal pressure). It appears that the IM is at least partially supported, but more research is needed to clarify the relationships between the core constructs of the IM since the overall empirical attention that the IM has been given is still very modest. As mentioned before, the IM was developed and tested in forensic psychiatric patients indicating the need for further testing in other patient populations.

\subsubsection{Intervention Strategies and Evidence for these Strategies}

As the IM is a continuous model with multiple determinants forming the basis for the level of motivation, interventions based on this model would include influencing these determinants. Drieschner and Verschuur [53] have argued that most of the internal determinants can be influenced by interventions such as motivational interviewing and its derivative motivational enhancement therapy, a general motivational style or by adherence to the responsivity principle (i.e. adapting the treatment to a patient's learning style, cultural background and cognitive capacity). The authors of IM have not proposed their own specific intervention based on the theory, so evidence for the efficacy of IM-compatible interventions comes indirectly. For example, motivational interviewing has been shown to be an effective intervention across different health behaviours, including alcohol, drugs and exercise [59]. At the moment, it is unclear whether motivational interviewing should be supported to use in treatments of individuals with severe mental illness or those with a dual diagnosis since evidence from randomised trials is inconsistent [60-61].

\subsection{Self-Determination Theory (SDT)}

Self-Determination Theory (SDT) was developed by Deci and Ryan [16]. SDT poses that all humans are naturally active organisms, focused on growing, mastering challenges and integrating new experiences into a coherent sense of self [16-17]. The social context is seen as a crucial influence upon the direction of this growth; it can either support it or hinder/stop it. According to SDT, this interplay between the active human and the social context determines behaviour and development. More specifically, SDT uses the concept of basic psychological needs for autonomy, competence and relatedness as the core ingredients for a healthy physical and mental development. If these basic psychological needs are 


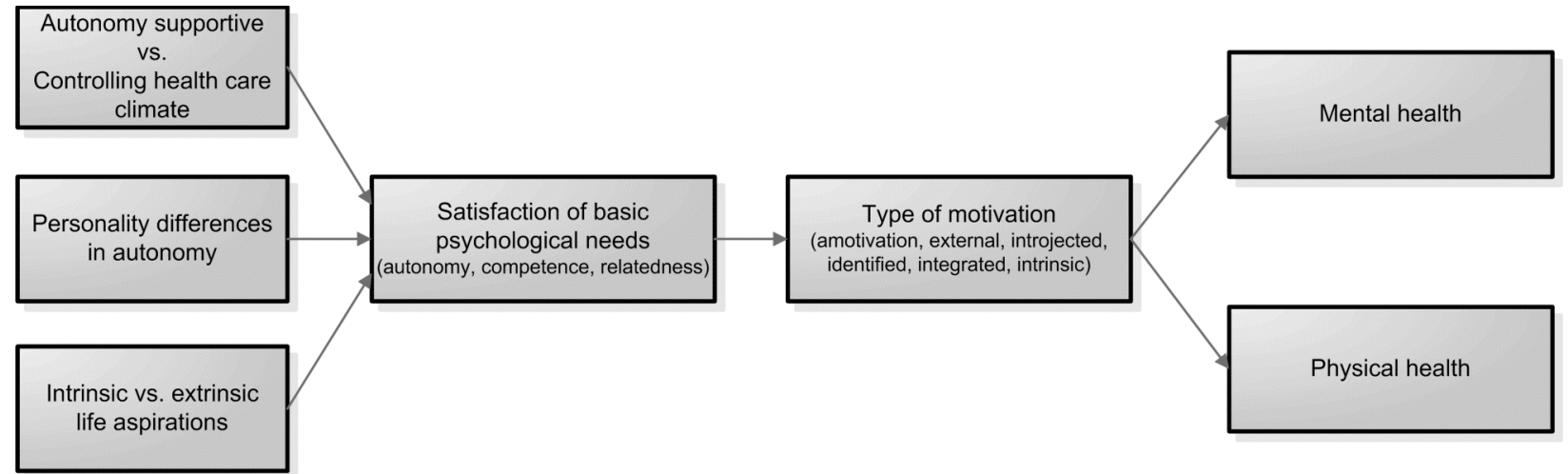

Fig. (3). Self-Determination Theory, adapted from Deci and Ryan [16] and Ryan, Patrick, Deci and Williams [62].

not met, certain types of psychopathology may develop [18]. Figure 3 visualises how SDT is modelled.

According to SDT, autonomous motivation may vary from intrinsic motivation to types of extrinsic motivation in which people have identified with the value of a change and have integrated this change into their sense of self [18]. SDT poses that autonomously motivated people experience greater ownership of the behaviour and feel less conflict about behaving in accord with regulations and external demands. For example, an individual who remains in a programme or treatment because he feels that following the treatment itself is exciting and pleasant (e.g. in a physical exercise programme), would be an autonomously motivated client. Obviously not many clients, if any, will present with such a motivation for psychiatric treatment, as treatment is usually followed with the goal of finding relief of symptoms or resolving problems and is usually not considered to be pleasant in itself. In contrast, controlled motivation consists of external regulation, in which behaviour is regulated by external rewards or punishments. When people have a controlled motivation, they experience pressure to behave in particular ways. SDT then differentiates four types of extrinsic motivation: external regulation, introjected regulation, identified regulation and integrated regulation. External regulation, in which people engage in an activity out of social pressure or to obtain an external reward or avoid punishment, is the least self-determined form of extrinsic motivation. In this case, the patient following psychiatric treatment would be motivated to remain in treatment because he feels pressured by others to do so (e.g. they advised him to do so). Next, introjected motivation is a more self-integrated form of extrinsic motivation. Instead of being motivated by external contingencies and forces, a person who behaves due to introjected motivations is driven by internal drives such as feelings of guilt, shame, and anxiety. A patient with such a drive would feel disappointed in himself or ashamed if he would not remain in treatment. SDT states that these motivational forces still remain external to person's self, because the individual does not fully endorse them. Moving further along the continuum, identified motivation is the third form of extrinsic motivation, in which the individual recognises and accepts the underlying value of certain behaviour. As Deci and Ryan [16] state it: "By identifying with a behaviour's value, people have more fully internalized its regula- tion; they have more fully accepted it as their own"(p.236). The resulting behaviour would be more autonomous, although still instrumental rather than integrated into the individual's sense of self. Finally, the most complete form of internalisation of extrinsic motivation is integrated motivation. Integrated motivation not only involves identifying with the importance of the behaviour, but is also about integrating those identifications with other aspects of the self. A separate category of motivation exists for people who experience no regulation at all (neither external nor internal) over their behaviour, and therefore lack any intention to behave in a certain way. This state is called amotivation. In this case, the patient is likely to reject or drop out from treatment soon. According to SDT, amotivation may be caused by a lack of self-efficacy and an external locus of control [16].

Theoretically, SDT is appealing because of its addition of a qualitative aspect to the motivation concept. The differentiation between different types of motivation, especially different types of extrinsic motivation, could prove beneficial and relevant for use in a context of patients with motivational issues such as those with SMI. To know not only the level of motivation of the patient but also the reasons behind it, could help clinicians to better guide patients towards resolutions of possible motivational conflicts while moving towards the desired behaviour change. However, as we shall discuss in the following, SDT has not (yet) been able to produce a measure that can assess all six types of motivation to engage in treatment.

\subsubsection{Definition and Measurement of the Constructs in SDT}

Within SDT, different constructs are operationalised by different measures. A separate scale was developed to study motivation for entering psychiatric treatment. This scale, called the Treatment Motivation Questionnaire (TMQ), has been studied in patients with alcohol addiction [63], in a study of people attending a methadone clinic [64] and among people with severe and persistent mental illness [65]. In this latter study, adult patients with a psychotic disorder or with a major mood disorder with psychotic features were assessed with an adapted version of the original TMQ. The original TMQ consists of 26 items reflecting four theoretical constructs: intrinsic motivation, extrinsic motivation, helpseeking and confidence in success of treatment. In the 
adapted version of the TMQ for the population of people with SMI, a five-factor solution was found in which an additional introjected motivation subscale was identified [65]. This version of the TMQ still provided support for the SDT framework in which external motivation was found to be an overarching construct comprising several sub-dimensions of emotion regulators (i.e. external motivation and introjected motivation). Furthermore, Wild, Cunningham and Ryan [66] have developed the Treatment Entry Questionnaire (TEQ) for patients in addiction treatment. The TEQ is an adapted version of the TMQ, including more items to be able to more clearly discriminate between identified, introjected and external motives for treatment. The TEQ formed internally consistent dimensions for external $(\alpha=.89)$, introjected $(\alpha=$ $.89)$ and identified motivation $(\alpha=.85)$. As mentioned previously, a disadvantage of using the TMQ or TEQ is that it does not assess all six types of motivation. Also, the TMQ and TEQ have thus far not become commonly used with any population and studies supporting the use of these questionnaires come primarily from the same source, the people who have developed SDT [67]. Although the TMQ appears to be a valid measure to use in a population of patients with SMI [65], it is unclear whether this is also the case for the extended version (the TEQ).

\subsubsection{Prediction of Treatment Engagement and Outcomes}

According to SDT, the more internal (i.e. autonomous) perceived cause of a person's behaviour, the more likely the person is to persist in this behavioural activity, and in case of treatment, to adhere to a therapeutic regimen. Conversely, the more external perceived cause of behaviour, or the more a person's reasons for entering treatment are based on external regulators (controlled motivation), the less persistence and adherence are expected. Several studies have supported these predictions from SDT, although only few studies have been conducted among patients with (severe) mental illness. A study by Zuroff et al. [68] showed that autonomous motivation was a stronger predictor of outcome in depressed outpatients than therapeutic alliance, predicting higher probability of achieving remission and lower posttreatment depression scores across three different treatments (interpersonal therapy, cognitive-behavioural therapy and pharmacotherapy with clinical management). Also, patients who reported their therapists as more autonomy supportive also reported higher levels of autonomous motivation [68]. A study by Pelletier, Tusson and Haddad [69] showed that the more autonomous patients were in their motivation for psychotherapy, the more satisfied they were with treatment, the greater their intention to persist and the lower their level of depressive symptoms. In contrast, controlled motivation was related to tension, and negatively predicted the importance of therapy and intention to persist [69]. Another study showed that higher need satisfaction for autonomy was related to improved outcomes in group psychotherapy for anxious and depressed patients, and this relation was presumably mediated by more treatment engagement and a reduction in negative thinking induced by cognitive behavioural therapy [70]. In a study with patients entering addiction treatment, Wild et al. [66] showed that external motivation was positively correlated with legal referral and social network pressures, while identified motivation was positively correlated with self-referral. Furthermore, it appeared that identified motivation predicted attempts to reduce drinking and drug use, more strongly than external motivation. Since patients with (severe) mental illness frequently have a co-occuring substance use disorder [71], these findings from SDT show promise for its use in this population. However, empirical evidence is still scarce, largely cross-sectional and the use of SDT within psychotherapy has mainly been promoted by the theorists (e.g. by Ryan \& Deci [72]). Furthermore, two studies have produced results that were not predicted by SDT. In a study by Ryan et al. [63] among patients with alcohol dependence, results revealed an interaction effect between internalised and external motivations, indicating that those with both high internal and high external reasons were most likely to persist in treatment. Another study replicated this in a methadone treatment programme, where it was found that external motivation accompanied by internal motivation may aid recovery of addiction [64]. This interaction between internal and external motivation is a finding that was not predicted by SDT, since the theory holds that external motivation would be related to less persistent engagement and poorer health outcomes. In fact, these results might be better explained by a quantitative motivation theory such as IM, where a higher level of motivation (i.e. a combination of high external and internal motives) is related to better outcomes.

\subsubsection{Intervention Strategies and Evidence for these Strategies}

SDT holds that social contexts that support satisfaction of the basic psychological needs facilitate the internalisation of extrinsic motivations [16]. That is, the social environment can facilitate satisfaction of the basic needs of autonomy, competence and relatedness by providing autonomy support, structure, and involvement, respectively. For example, competence is facilitated when patients are helped to develop clear and realistic expectations and goals about behaviour change, they are encouraged to believe that they are capable of engaging in appropriate behaviours, and are given positive feedback regarding their progress [18]. However, providing support for only one basic need such as competence is insufficient to promote internalisation of motivation [16]. A motivationally supportive environment provides support for autonomy, competence as well as relatedness [16]. The need for autonomy is supported when patients are helped to develop a personally meaningful rationale for engaging in behaviour, by minimising external controls and contingencies upon the behaviour, by providing opportunities for active participation and choice and by acknowledging negative feelings associated with engaging in appropriate behaviour that is difficult to accomplish [73]. In SDT the role of relatedness and involvement has received less attention than autonomy and competence, but involvement describes the extent to which patients perceive that significant others are genuinely interested in them and their well-being, understand the difficulties they are facing, and are emotionally supportive [16].

Several studies have found support for SDT's prediction that perceived autonomy support facilitates the development of more autonomous motives for change [64, 74-78]. However, of the randomised controlled trials that have been con- 
Table 1. Evaluation criteria applied to the three motivation theories in the context of psychiatric treatment motivation, showing their strong (+) and weak/not sufficiently determined (-) points

\begin{tabular}{|c|c|c|c|c|}
\hline Criterion & Description & TTM & IM & SDT \\
\hline Clarity & $\begin{array}{l}\text { Has well-defined terms that are } \\
\text { operationalised and explicit and } \\
\text { internally consistent. Explicit } \\
\text { propositions are preferred. }\end{array}$ & $\begin{array}{l}\text { + Explicit terms are operationalised } \\
\text { - Debate about the operationalisation of the stages of } \\
\text { change } \\
\text { - Propositions regarding processes of change not } \\
\text { always clear (e.g. are they mediators or moderators?) }\end{array}$ & $\begin{array}{l}\text { + Explicit terms are } \\
\text { operationalised } \\
\text { - Unclear proposition } \\
\text { about role of 'external } \\
\text { factors' }\end{array}$ & $\begin{array}{l}\text { + Explicit terms and proposi- } \\
\text { tions } \\
\text { - Not all terms operationalised } \\
\text { (e.g. all types of motivation) } \\
\text { - No proposition for the com- } \\
\text { bination of high autonomous } \\
\text { and high external motivation }\end{array}$ \\
\hline Consistency & $\begin{array}{l}\text { The components do not contra- } \\
\text { dict each other. There is fit } \\
\text { between concepts, propositions } \\
\text { and clinical exemplars. }\end{array}$ & + Good fit between concepts and clinical exemplars & $\begin{array}{l}+ \text { Good fit between con- } \\
\text { cepts and propositions }\end{array}$ & $\begin{array}{l}+ \text { Good fit between concepts } \\
\text { and propositions }\end{array}$ \\
\hline Parsimony & $\begin{array}{l}\text { Explains the phenomenon in the } \\
\text { least complex manner possible. }\end{array}$ & $\begin{array}{l}\text { + Separate constructs easy to understand } \\
\text { - Complex model with many interrelations between } \\
\text { constructs }\end{array}$ & $\begin{array}{l}\text { + Distinction between } \\
\text { determinants and conse- } \\
\text { quences of motivation } \\
\text { - Large number of deter- } \\
\text { minants }\end{array}$ & $\begin{array}{l}\text { + Simple model, easy to under- } \\
\text { stand }\end{array}$ \\
\hline Testable & $\begin{array}{l}\text { The propositions can be tested, } \\
\text { with the potential to be falsifi- } \\
\text { able or refuted. }\end{array}$ & + & + & + \\
\hline $\begin{array}{l}\text { Empirical valid- } \\
\text { ity }\end{array}$ & $\begin{array}{l}\text { The theoretical claims are con- } \\
\text { gruent with evidence. }\end{array}$ & $\begin{array}{l}\text { + Many studies have been done across different life } \\
\text { domains } \\
\text { - Mixed evidence is found } \\
\text { - Little research has been done in populations of } \\
\text { patients with SMI }\end{array}$ & $\begin{array}{l}\text { + Predictive power con- } \\
\text { firmed in forensic psychi- } \\
\text { atric patients } \\
\text { - Few amount of studies } \\
\text { - No research has been } \\
\text { done outside forensic } \\
\text { setting }\end{array}$ & $\begin{array}{l}\text { + Many studies have been done } \\
\text { across different life domains } \\
\text { - Little research has been done } \\
\text { in populations of patients with } \\
\text { SMI }\end{array}$ \\
\hline Productivity & $\begin{array}{l}\text { Reveals new phenomenon or } \\
\text { relations among those already } \\
\text { known. Generates new questions } \\
\text { and ideas and adds to the knowl- } \\
\text { edge base. }\end{array}$ & $\begin{array}{l}+ \text { Generates new ideas and has added to knowledge } \\
\text { base } \\
+ \text { Heuristic value }\end{array}$ & $\begin{array}{l}\text { - Small addition to knowl- } \\
\text { edge base (relatively new } \\
\text { theory) }\end{array}$ & $\begin{array}{l}+ \text { Generates new ideas and has } \\
\text { added to knowledge base }\end{array}$ \\
\hline Generalisable & $\begin{array}{l}\text { Generalises to other situations, } \\
\text { places and times. Extends far } \\
\text { beyond particular observations } \\
\text { and laws that it was designed to } \\
\text { explain. }\end{array}$ & $\begin{array}{l}\text { + Applied to broad range of behaviours (e.g. smok- } \\
\text { ing, diet, exercise, condom use, drug abuse) }\end{array}$ & $\begin{array}{l}\text { - Specific theory about } \\
\text { motivation for psychiatric } \\
\text { treatment }\end{array}$ & $\begin{array}{l}\text { + Applied to broad range of } \\
\text { behaviours (e.g. parenting, } \\
\text { education, exercise, work, } \\
\text { health) }\end{array}$ \\
\hline Integration & $\begin{array}{l}\text { A set of constructs are combined } \\
\text { in systematic and meaningful } \\
\text { patterns, first conceptually, then } \\
\text { empirically, and ideally mathe- } \\
\text { matically. }\end{array}$ & $\begin{array}{l}\text { + Meaningful conceptualisation } \\
+ \text { The initial model was adjusted to empirical evi- } \\
\text { dence } \\
+ \text { Strong and weak principle (mathematical pattern) } \\
\text { - Empirical pattern of processes of change less clear }\end{array}$ & $\begin{array}{l}\text { + Meaningful conceptu- } \\
\text { alisation } \\
+ \text { The initial model was } \\
\text { adjusted to empirical } \\
\text { evidence } \\
\text { - No mathematical princi- } \\
\text { ple }\end{array}$ & $\begin{array}{l}\text { + Meaningful conceptualisa- } \\
\text { tion } \\
+ \text { The initial model was ad- } \\
\text { justed to empirical evidence } \\
\text { - No mathematical principle }\end{array}$ \\
\hline Utility & Provides service and is useable. & + One of the most widely used and influential models & $\begin{array}{l}\text { + Provides service to } \\
\text { specific population } \\
\text { - Few empirical tests }\end{array}$ & $\begin{array}{l}\text { + Utility has increased the last } \\
\text { two decades }\end{array}$ \\
\hline Practical & $\begin{array}{l}\text { A theory-based intervention is } \\
\text { demonstrated to have significant } \\
\text { efficacy, producing greater } \\
\text { behaviour change than a placebo } \\
\text { or control. }\end{array}$ & $\begin{array}{l}\text { + Appeals to clinicians and is most commonly used } \\
\text { theory across a broad range of behaviours } \\
\text { - Mixed evidence is found } \\
\text { - No evidence for practical use in patients with SMI }\end{array}$ & $\begin{array}{l}\text { - Theory does not imply a } \\
\text { specific intervention }\end{array}$ & $\begin{array}{l}+ \text { Theory-based intervention } \\
\text { efficacious for } \\
\text { tobacco dependence, physical } \\
\text { activity and dental hygiene } \\
\text { - No evidence for practical use } \\
\text { in patients with SMI }\end{array}$ \\
\hline
\end{tabular}

ducted to investigate this hypothesis from SDT, none have so far focused upon patients with (severe) mental illness. Therefore, SDT is in need of prospective investigations and randomised trials to see whether the theory's predictions hold for this population.

\section{CRITICAL REFLECTION UPON THE THREE THEORIES}

Table 1 shows the most common evaluation criteria that are used to evaluate the quality of theories, which we adapted from Prochaska, Wright and Velicer [79]. Several points that are noted in this table should be explained. For 
Table 2. Comparing Core Constructs Across the Three Motivation Theories

\begin{tabular}{|c|c|c|c|}
\hline Concept & $\begin{array}{c}\text { Integral Model of treatment moti- } \\
\text { vation }\end{array}$ & $\begin{array}{c}\text { TransTheoretical Model (Stages of } \\
\text { Change) }\end{array}$ & Self-Determination Theory \\
\hline \multicolumn{4}{|l|}{ Attitudinal beliefs } \\
\hline $\begin{array}{l}\text { Beliefs about the efficacy of the } \\
\text { treatment }\end{array}$ & Perceived suitability of treatment & - & - \\
\hline \multicolumn{4}{|l|}{ Self-efficacy beliefs } \\
\hline $\begin{array}{l}\text { Belief in one's ability to perform } \\
\text { the behaviour; confidence }\end{array}$ & $\begin{array}{l}\text { Self-efficacy } \\
\text { (as a part of outcome expectancy } \\
\text { within the internal determinants) }\end{array}$ & Self-efficacy & Perceived competence* \\
\hline \multicolumn{4}{|l|}{ Emotional responses } \\
\hline $\begin{array}{l}\text { Experiencing negative emotions } \\
\text { due to the problem behaviour and } \\
\text { coping with these emotions }\end{array}$ & $\begin{array}{l}\text { Distress } \\
\text { (internal determinant) }\end{array}$ & $\begin{array}{l}\text { Dramatic relief and Self-re- } \\
\text { evaluation } \\
\text { (experiential process of change) }\end{array}$ & $\begin{array}{l}\text { Introjected regulation } \\
\text { (type of regulation) }\end{array}$ \\
\hline \multicolumn{4}{|l|}{ Motivation } \\
\hline $\begin{array}{l}\text { Not intending to perform the } \\
\text { behaviour, not making commit- } \\
\text { ments to change }\end{array}$ & $\begin{array}{l}\text { Low motivation to engage in treat- } \\
\text { ment }\end{array}$ & $\begin{array}{l}\text { Precontemplation } \\
\text { (stages of change) }\end{array}$ & Amotivation \\
\hline \multicolumn{4}{|l|}{ Outcome } \\
\hline $\begin{array}{l}\text { Long-term outcome of the behav- } \\
\text { iour }\end{array}$ & Treatment outcome & $\begin{array}{l}\text { Maintenance and termination } \\
\text { (stages of change) }\end{array}$ & Treatment outcome \\
\hline
\end{tabular}

example, although all three theories have clear and welldefined concepts, the TTM and SDT have issues pertaining to the operationalisation of constructs (i.e. how the stages of change should be measured and that not all motivational types are present in current measures, respectively) and some of the propositions of the IM and TTM are unclear. All three theories are productive and provide ideas that generate research. For example, TTM provides a temporal framework for motivation as represented by the stages of change, whereby engaging in the processes of change would predict stage movements. The IM disentangles the determinants of motivation from its effects (different from TTM) and views motivation as a primarily quantitative concept (similar to TTM). Finally, SDT appears to differentiate itself from these two theories with its postulation of basic psychological needs that determine the development of specific types of motivation (amotivation, external, introjected, identified, integrated and intrinsic motivation) which in turn predict treatment engagement and outcomes. All models are testable but as far as empirical tests of the theories have been conducted among individuals with SMI, it appears that the findings show mixed evidence for the theories' predictive and explanatory strengths. 
Taking these critical points together, it is difficult to conclude which theory is overall currently superior to the other theories in the context of psychiatric treatment motivation and engagement. For TTM, long-standing issues pertaining to the measurement and distinctiveness of the stages of change and the relatively little empirical attention that has been dedicated to the processes of change currently appear to stand in the way of theoretical advancement for this theory. Also, empirical support for the hypothesis that matching interventions to specific TTM stages is beneficial appears to be lacking $[13,47,50]$ and application of stage-matched interventions to patients with SMI thus seems premature. The IM has only been studied in a forensic psychiatric setting and although these findings show promise for its application in other populations, the current value for patients with SMI is unknown. Regarding SDT, the scarce empirical evidence that is available regarding patients with mental illness shows general support for the theory, but no longitudinal studies have yet been conducted among patients with SMI indicating the need for further investigations.

The question whether a continuous model (i.e. IM or SDT) or a stage-based theory (i.e. TTM) is most valuable to use as a basis for the improvement of treatment engagement and treatment outcomes in patients with (severe) mental illness appears to fall in favour of continuous models, although it should be noted that all three theories have been scarcely investigated among individuals with SMI. Littell and Girvin [13] have argued that: "Although a stage model may have greater intuitive appeal, a continuous model of readiness for change is more parsimonious and may be more easily integrated with related concepts from other theories. (...) A continuous model may fit the data better than a stage model, although continuous measures of readiness for change have not yet been thoroughly tested" (p. 253).

The question whether a quantitative approach or qualitative approach to motivation is superior for the prediction of treatment engagement remains to be answered, since all three theories have thus far shown mixed findings. For example, we have shown that research findings that were not well predicted by IM could be explained by SDT and vice versa. One study by Vansteenkiste et al. [80] has readily addressed the question of quantity versus quality of motivation in a sample of high school and college students, to see which approach best predicted optimal learning patterns. Four motivation profiles were constructed from a SDT perspective: a good quality motivation group (i.e., high autonomous, low controlled); a poor quality motivation group (i.e., low autonomous, high controlled); a low quantity motivation group (i.e., low autonomous, low controlled); and a high quantity motivation group (i.e., high autonomous, high controlled). The authors compared predictions from qualitative and quantitative perspectives on motivation and found that compared with the other profiles, the good quality motivation group showed the most optimal learning pattern [80]. Such an approach adapted to motivation for treatment in patients with (severe) mental illness could shed more light on the qualitative versus quantitative debate with respect to the prediction of treatment engagement and outcomes.

In the following, we intend to relate the three theories to each other, in order to further disentangle their common and unique contributions to the motivation concept. In doing so, we hope to demonstrate that the theories are generally compatible with each other and can be studied simultaneously to address relevant research questions.

\subsection{Compatibility of Constructs Within the Theories}

The core constructs of the TTM, IM and SDT can be disentangled into seven common domains: (1) attitudinal beliefs, (2) self efficacy beliefs, (3) reinforcements and environmental influences, (4) emotional responses, (5) motivation, (6) behaviour and (7) outcome. These domains have been summarised in Table 2 where similar constructs across the theories are compared in the rows. For example, when the decisional balance construct of TTM is specifically applied to psychiatric treatment engagement, where patients evaluate whether or not to engage in their treatment, decisional balance is comparable to the constructs called 'perceived costs of treatment' and 'outcome expectancy' in IM, since they are concerned with appraisal of the positive and negative aspects of treatment engagement. Furthermore, it appears that self-efficacy, broadly defined as the belief that one is capable or competent in achieving desirable behaviour, is incorporated in all three theories albeit in different ways. For example, SDT holds that self-efficacy needs to be combined with a sense of autonomy in order to achieve the most positive outcomes [16] whereas the IM and TTM do not appear to make such a distinction.

Also interesting is that within SDT, a distinction is made between short-term and long-term effects of reinforcements. According to SDT, reinforcements facilitate external motivation which may lead to short-term behaviour change but will show poor maintenance and transfer once contingencies and external pressure are withdrawn. SDT states that rewards and threats undermine autonomy and thus lead to decreased intrinsic motivation and more negative outcomes [16]. Contrasting this is the view of TTM, where reinforcement management would predict movement from the action to the maintenance stage. Thus, interventions based on TTM would include rewarding the patient for making beneficial changes and stimulate the patient to reward himself for making changes. Interventions based on SDT would not include reinforcements as these external regulations are often experienced as controlling one's behaviour [81] and are counterproductive for the development of intrinsic motivation, leading to poor maintenance of the behaviour change. Interestingly, DiClemente (1999) has noted that intrinsic and extrinsic motivation types differ with regard to their long-term outcomes and that: "personal pros and cons are more important than external incentives in the long run. Sustained change must be reinforced by incentives that are owned by the individual, so that they become integrated into the life of that individual" (p.211). Nevertheless, this insight has not yet established itself in the form of an adaptation of TTM. It appears that both TTM and IM expect that the level of motivation will increase when strategies such as rewards (reinforcements) and threats (legal pressure) are applied, whereas SDT predicts differential effects on the type of motivation (and subsequent behaviour) that will result from these strategies. These different predictions call for empirical tests, as do other research questions regarding the three theories that have been summarised in Table 3 . 
Table 3. Possible Research Questions Pertaining to TTM, IM and SDT in the Context of Psychiatric Treatment for Patients with Severe mental Illness

\begin{tabular}{|c|c|}
\hline Theory & Research questions \\
\hline TTM & $\begin{array}{l}\text { Do stage algorithms or continuous measures of the stages of change provide better prediction of treatment engagement and out- } \\
\text { comes? } \\
\text { Do the processes of change predict stage transitions for patients with SMI? } \\
\text { Do SMI patients in psychiatric treatment in lower stages show higher rates of drop-out than patients in higher stages? }\end{array}$ \\
\hline IM & $\begin{array}{l}\text { Are the TMS-f and TER valid and reliable measures in patients with SMI? } \\
\text { What factors, apart from the level of motivation to engage in treatment, are predictive of actual treatment engagement in patients with } \\
\text { SMI? } \\
\text { Does the level of motivation to engage in treatment have predictive value for treatment engagement and outcome in patients with } \\
\text { SMI? }\end{array}$ \\
\hline SDT & $\begin{array}{l}\text { Is it possible to distinguish the six types of motivation as postulated by SDT? } \\
\text { Is the TEQ a valid and reliable measure for patients with SMI? } \\
\text { Do the motivational types from SDT have predictive value regarding treatment engagement and treatment outcomes in patients with } \\
\text { SMI? } \\
\text { Does the support of the basic psychological needs predict internalisation of motivation in patients with SMI? }\end{array}$ \\
\hline $\begin{array}{l}\text { Theory compari- } \\
\text { sons }\end{array}$ & $\begin{array}{l}\text { Does the stage-based TTM or the continuum-based IM provide better prediction of treatment engagement and outcomes in patients } \\
\text { with SMI? } \\
\text { Does a quantitative approach to motivation provide better prediction of treatment engagement than a qualitative approach? } \\
\text { Is there a difference between self-efficacy (TTM and IM) and perceived competence (SDT)? } \\
\text { Are similar constructs from the different theories (see table 2) actually identical? } \\
\text { Is reinforcement management predictive of the quantity and quality of motivation? } \\
\text { Is reinforcement management predictive of long-term treatment engagement and outcomes? } \\
\text { Are the relations between the three theories as proposed by figure } 4 \text { in this article supported by empirical evidence? For example; } \\
\text { - Is the level of MET (IM) related to the stages of change (TTM)? } \\
\text { - Is the level of treatment engagement (IM) related to stages of change (TTM)? } \\
\text { - Is SDT's internalisation process related to the stages of change (TTM)? } \\
\text { - Are the internal determinants (IM) related to different motivational types (SDT)? }\end{array}$ \\
\hline
\end{tabular}

TTM: TransTheoretical Model; IM: Integral Model of treatment motivation; SDT: Self-Determination Theory; SMI: Severe Mental Illness; TMS-f: Treatment Motivation Scales for Forensic outpatient treatment; TER: Treatment Engagement Rating scale; TEQ: Treatment Entry Questionnaire; MET: Motivation to engage in treatment.

\subsection{Compatibility of the Three Theories}

In Figure 4, we have visualised how all three models might relate to each other. To start at the top of the figure with the IM, this model clearly distinguishes the determining factors of motivation to engage in treatment (MET) from its manifestation into behaviour. This way, the model provides reasons as to why an individual has a certain level of motivation for treatment. TTM does not incorporate the determinants of allocations to certain stages, although based on the descriptions of stages one could extract some. Rather, TTM describes when individuals change by engaging in change processes. It could be argued that at a conceptual level, moving from precontemplation through contemplation to preparation in TTM, the level of MET in the IM increases as we come closer to the actual action (active manifestation of the behaviour). For example, a low level of MET might correspond with either the precontemplation or contemplation phase, where patients are unwilling or not ready to engage in behaviour change, but have been thinking about it. Also, a high level of MET could correspond with later stages such as the preparation or action stage.

In SDT, the motivation concept revolves primarily around the type of motivation. This conceptualisation of motivation is clearly distinct from the other models. Neverthe- less, some authors have hypothesised links between SDT and TTM and have proposed SDT's internalisation process to be associated with stage movement within TTM (e.g. Dunlap [35], Kennedy \& Gregoire [67], Vansteenkiste, Soenens and Vandereycken [82] and Abblett [83]). Vansteenkiste et al. [82] have argued that TTM seems compatible with the concept of internalisation of change and thus with the idea of the types of motivation within SDT. However, from an SDT perspective the critical question would not be to which extent patients find themselves in a certain stage, but why they are in that stage. There is some preliminary evidence that as internalisation increases, so does the individual's advancement along the TTM stages [35, 67, 83, 84]. For example, it has been found that people entering drug abuse treatment with high levels of internal motivation were more likely to be in the action stage than people with high levels of external motivation [67]. In another study, it was found that the use of more identified and intrinsic forms of behaviour regulation distinguished those in action and maintenance stages from those in contemplation and preparation stages [84]. These findings suggest that the level of internalisation differs for people in different stages of change, where amotivated or externally regulated individuals might be more prevalent in the precontemplation stage, whereas individuals who have an integrated form of motivation might be more prevalent in 


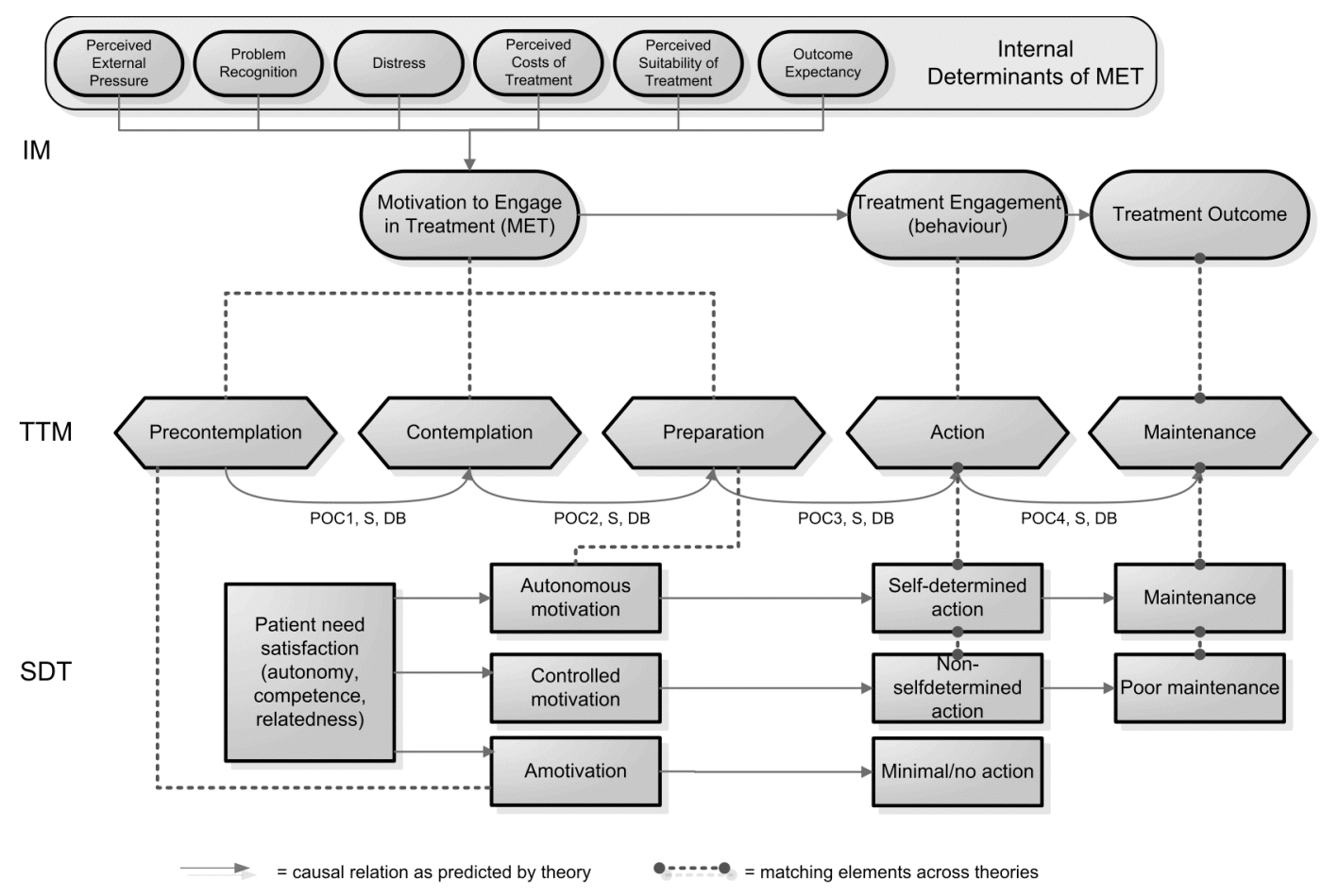

Fig. (4). Visualisation of the three motivation theories and their interrelations

IM: Integral Model; TTM: TransTheoretical Model; POC1: Processes of change (consciousness raising, dramatic relief); POC2: Processes of change (self-reevaluation); POC3: Processes of change (self-liberation); POC4: Processes of change (reinforcement management, helping relationships, counterconditioning, stimulus control); S: Self-efficacy; DB: Decisional Balance; SDT: Self Determination Theory.

action and maintenance stages. In Figure 4, this relationship between the models is represented by the dotted lines between the precontemplation phase in TTM and amotivation in SDT, and the dotted line between the preparation stage and intrinsic motivation, respectively. Abblett [83] describes SDT as providing the molecular mechanisms of how motivation is created, and TTM as providing an infrastructure for understanding the processes of change. Also, where in the IM and TTM it seems relatively important that a person engages in treatment, in SDT it is important how (selfdetermined) a person engages in his/her treatment. Some interesting research questions pertaining to these three theories and their interrelations are presented in Table 3. It should be noted that Noar and Zimmerman [1] have also suggested important theory comparison questions which could be applied to these three theories.

\section{CONCLUSION}

The TTM, IM and SDT provide distinct, but in our view compatible conceptualisations of treatment motivation. The TTM provides a temporal framework for motivation as represented by the stages of change, in which cognitive and behavioural components have been recognised $[9,24]$ while IM disentangles the determinants of motivation from its effects. SDT appears to differentiate itself from these two theories with its postulation of basic psychological needs that determine the development of specific types of motivation for particular behaviours. The theories include several common theoretical constructs such as self-efficacy and reinforcement strategies, but sometimes predict different effects of these constructs upon treatment engagement and outcomes. For example, although all three theories acknowledge that reinforcement strategies have an effect upon motivation and treatment engagement, TTM and IM predict that reinforcements lead to a higher level of treatment motivation and better maintenance of the desired behaviour, while SDT holds that reinforcements undermine the development of more autonomous motivation and thus ultimately to poor maintenance of the desired behaviour.

At present it remains unclear which theory is most effective in predicting behaviour change and maintenance, and also which theory is best suited for use within clinical practice. Future research should focus upon empirical comparisons of these (and other) theories, in order to aid optimal decision making on which theories are most plausible and most useful for clinical practice. A comparison of theories is a complex challenge, but several authors have reflected upon this and provided guidelines [1-3, 85]. To reduce patient burden, comparable constructs from different theories could be assessed with a single measure. For example, this could apply to the decisional balance constructs and problem recognition, and possibly also for the patients perception of external pressures and social relations. The unique aspects of the theories ask for theory-specific measures, such as the stages of change within TTM, perceived suitability of treatment within IM, and different motivational types within SDT. To conclude, it is of particular interest to design and conduct theory comparison studies among subgroups of patients, such as those with severe mental illness, to advance what is currently known about how well the TTM, IM and 
SDT account for intrapersonal changes and interpersonal differences in treatment engagement and treatment outcome. In turn, this could aid in the development of effective interventions to improve treatment retention and outcome.

\section{REFERENCES}

[1] Noar SM, Zimmerman RS. Health behavior theory and cumulative knowledge regarding health behaviors: Are we moving in the right direction? Health Educ Res 2005;20(3):275-90.

[2] Weinstein ND, Rothman AJ. Commentary: Revitalizing research on health behavior theories. Health Educ Res 2005;20(3):294-7.

[3] Weinstein ND. Misleading tests of health behavior theories. Ann Behav Med 2007;33(1):1-10.

[4] Lehner RK, Dopke CA, Cohen K, et al. Outpatient treatment adherence and serious mental illness: A review of interventions. Am J Psychiatr Rehabil 2007;10(4):245-74.

[5] Centorrino F, Hernan MA, Drago-Ferrante G, et al. Factors associated with noncompliance with psychiatric outpatient visits. Psychiatr Serv 2001;52(3):378-80.

[6] Barrett MS, Chua WJ, Crits-Christoph P, Gibbons MB, Casiano D, Thompson D. Early withdrawal from mental health treatment: Implications for psychotherapy practice. Psychotherapy 2008;45(2):247-67.

[7] McMurran M, Huband N, Overton E. Non-completion of personality disorder treatments: A systematic review of correlates, consequences, and interventions. Clin Psychol Rev 2010;30(3):277-87.

[8] Prochaska JO, DiClemente CC. Stages and processes of selfchange in smoking: Toward an integrative model of change. Journal of Consulting and Clinical Psychology 1983;5:390-5.

[9] Drieschner KH, Lammers SMM, van der Staak CPF. Treatment motivation: An attempt for clarification of an ambiguous concept. Clin Psychol Rev 2004;23(8):1115-37.

[10] Tierney DW, McCabe MP. The validity of the trans-theoretical model of behaviour change to investigate motivation to change among child molesters. Clin Psychol Psychot 2001;8:176-90.

[11] Prochaska JO, DiClemente CC, Norcross JC. In search of how people change: Applications to addictive behaviors. J Addict Nurs 1992;5(1):2-16.

[12] West R. Time for a change: Putting the transtheoretical (stages of change) model to rest. Addiction 2005;100(8):1036-9.

[13] Littell JH, Girvin H. Stages of change: A critique. Behav Modif 2002;26(2):223-73.

[14] Guo B, Aveyard P, Fielding A, Sutton S. Do the transtheoretical model processes of change, decisional balance and temptation predict stage movement? Evidence from smoking cessation in adolescents. Addiction 2009;104(5):828-38.

[15] Weinstein ND, Rothman AJ, Sutton S. Stage theories of health behavior: Conceptual and methodological issues. Health Psychol 1998;17(3):290-9.

[16] Deci EL, Ryan RM. The "What" And "Why" Of goal pursuits: Human needs and the self-determination of behavior. Psychol Inq 2000;11(4):227 - 68 .

[17] Deci EL, Eghrari H, Patrick BC, Leone DR. Facilitating internalization: The self-determination theory perspective. J Pers 1994;62(1):119-42.

[18] Deci EL, Ryan RM. Self-determination theory: A macrotheory of human motivation, development, and health. Can Psychol 2008;49(3):182-5.

[19] Prochaska JO, Velicer WF. The transtheoretical model of health behavior change. Am J Health Promot 1997;12(1):38-48.

[20] Prochaska JO. Decision making in the transtheoretical model of behavior change. Med Decis Making 2008;28(6):845-9.

[21] Buckley PF, Wirshing DA, Bhushan P, Pierre JM, Resnick SA, Wirshing WC. Lack of insight in schizophrenia: Impact on treatment adherence. CNS Drugs 2007;21(2):129-41.

[22] Wright JA, Velicer WF, Prochaska JO. Testing the predictive power of the transtheoretical model of behavior change applied to dietary fat intake. Health Educ Res 2009;24(2):224-36.

[23] Prochaska JO, Redding CA, Evers KE. The transtheoretical model and stages of change. In: Glanz K, Rimer BK, Lewis M, Eds. Health behavior and health education: Theory, research and practice. San Francisco: Jossey-Bass; 2002. p. 60-84.
[24] Sutton S. Back to the drawing board? A review of applications of the transtheoretical model to substance use. Addiction 2001;96(1):175-86.

[25] Wilson GT, Schlam TR. The transtheoretical model and motivational interviewing in the treatment of eating and weight disorders. Clin Psychol Rev 2004;24(3):361-78.

[26] Sutton S. Can "Stages of change" Provide guidance in the treatment of addictions? A critical examination of prochaska and diclemente's model. In: Edwards G, Dare C, Eds. Psychotherapy, psychological treatments and the addictions. Cambridge, UK: Cambridge University Press; 1996. p. 189-205.

[27] Rollnick S, Heather N, Gold R, Hall W. Development of a short 'readiness to change' questionnaire for use in brief, opportunistic interventions among excessive drinkers. Brit J Addict 1992;87(5):743-54.

[28] McConnaughy EA, Prochaska JO, Velices WF. Stages of change in psychotherapy: Measurement and sample profiles. PsychotherTheor Res 1983;20(3):368-75.

[29] Simpson DD, Joe GW. Motivation as a predictor of early dropout from drug abuse treatment. Psychother 1993;30(2):357-68.

[30] Hodgins D. Stages of change assessments in alcohol problems: Agreement across self- and clinician-reports. Subst Abuse 2001;22(2):87-96

[31] Nidecker M, DiClemente CC, Bennett ME, Bellack AS. Application of the transtheoretical model of change: Psychometric properties of leading measures in patients with co-occurring drug abuse and severe mental illness. Addict Behav 2008;33(8):1021-30.

[32] Prochaska JO. Moving beyond the transtheoretical model. Addiction 2006;101(6):768-74.

[33] Velicer WF, DiClemente CC, Prochaska JO, Brandenburg N. Decisional balance measure for assessing and predicting smoking status. J Pers Soc Psychol 1985;48(5):1279-89.

[34] Prochaska JO, Velicer WF, DiClemente CC, Fava JL. Measuring processes of change: Applications to the cessation of smoking. Journal of Consulting and Clinical Psychology 1988;56(4):520-8.

[35] Dunlap SK. Internalization: A related process to stages-of-change among participants in a court-mandated substance abuse program. Diss Abstr Int 2010;70(7):4480-B.

[36] DiClemente CC. Conceptual models and applied research: The ongoing contribution of the transtheoretical model. J Addict Nurs 2005;16(1-2):5-12.

[37] Hutchison AJ, Breckon JD, Johnston LH. Physical activity behavior change interventions based on the transtheoretical model: A systematic review. Health Educ Behav 2009;36(5):829-45.

[38] Rogers E, Martin R, Anthony W, et al. Assessing readiness for change among persons with severe mental illness. Community Ment Health J 2001;37(2):97-112.

[39] Pantalon MV, Swanson AJ. Use of the university of rhode island change assessment to measure motivational readiness to change in psychiatric and dually diagnosed individuals. Psychol Addict Behav 2003;17(2):91-7.

[40] Gorczynski P, Faulkner G, Greening S, Cohn T. Exploring the construct validity of the transtheoretical model to structure physical activity interventions for individuals with serious mental illness. Psychiatr Rehabil J 2010;34(1):61-4.

[41] Bezyak JL. Stages of change and physical activity among individuals with severe mental illness. Diss Abstr Int 2009;69(9B):5766.

[42] Tsang HW-h, Fung KM-t, Chung RC-k. Self-stigma and stages of change as predictors of treatment adherence of individuals with schizophrenia. Psychiatry Res 2010;180(1):10-5.

[43] Velasquez MM, Carbonari JP, Diclemente CC. Psychiatric severity and behavior change in alcoholism: The relation of the transtheoretical model variables to psychiatric distress in dually diagnosed patients. Addictive Behaviors 1999;24(4):481-96.

[44] Hagedorn HJ. Application of the transtheoretical model of behavior change to cessation of alcohol use in patients with schizophrenia Diss Abstr Int 2000;61(3-B):1635.

[45] Carey KB, Purnine DM, Maisto SA, Carey MP. Correlates of stages of change for substance abuse among psychiatric outpatients. Psychol Addict Behav 2002;16(4):283-9.

[46] Project MATCH Research Group A. Project match (matching alcoholism treatment to client heterogeneity): Rationale and methods for a multisite clinical trial matching patients to alcoholism treatment. Alcohol Clin Exp Res 1993;17(6):1130-45. 
[47] Project MATCH Research Group A. Matching alcoholism treatments to client heterogeneity: Project match three-year drinking outcomes. Alcohol Clin Exp Res 1998;22(6):1300.

[48] Walters GD. Lessons learned from project match. Addictive Disorders \& Their Treatment 2002;1(4):135-9.

[49] Witkiewitz K, Hartzler B, Donovan D. Matching motivation enhancement treatment to client motivation: Re-examining the project match motivation matching hypothesis. Addiction 2010;105(8):1403-13.

[50] Bridle C, Riemsma RP, Pattenden J, et al. Systematic review of the effectiveness of health behavior interventions based on the transtheoretical model. Psychol Health 2005;20(3):283 - 301.

[51] Brogan MM, Prochaska JO, Prochaska JM. Predicting termination and continuation status in psychotherapy using the transtheoretical model. Psychother Theor Res Pract Train 1999;36(2):105-13.

[52] Patterson DA, Wolf S, Buckingham SL. Does motivational interviewing stages of change increase treatment retention among persons who are alcohol and other drug dependent and hiv infected? J HIV AIDS Soc Serv 2010;9(1):45-57.

[53] Drieschner KH, Verschuur J. Treatment engagement as a predictor of premature treatment termination and treatment outcome in a correctional outpatient sample. Crim Behav Ment Health 2010;20(2):86-99.

[54] Conner M, Norman P. Comparing the health belief model and the theory of planned behavior in health screening. In: Rutter DR, Quiine L, Eds. Social psychology and health: European perspectives. Brookfield: Avebury/Ashgate; 1994. p. 1-24.

[55] Sutton S. How does the health action process approach (hapa) bridge the intention-behavior gap? An examination of the model's causal structure. App Psychol-Int Rev 2008;57(1):66-74.

[56] Drieschner KH, Boomsma A. Validation of the treatment motivation scales for forensic outpatient treatment (tms-f). Assessment 2008;15(2):242-55.

[57] Drieschner KH, Boomsma A. The treatment motivation scales for forensic outpatient treatment (tms-f): Construction and psychometric evaluation. Assessment 2008;15(2):224-41.

[58] Drieschner $\mathrm{KH}$, Boomsma A. The treatment engagement rating scale (ter) for forensic outpatient treatment: Description, psychometric properties, and norms. Psychol Crime Law 2008;14(4):299 - 315.

[59] Burke BL, Arkowitz H, Menchola M. The efficacy of motivational interviewing: A meta-analysis of controlled clinical trials. J Consult Clin Psychol 2003;71(5):843-61.

[60] Drymalski WM, Campbell TC. A review of motivational interviewing to enhance adherence to antipsychotic medication in patients with schizophrenia: Evidence and recommendations. J Ment Health 2009;18(1):6-15.

[61] Martino S. Contemplating the use of motivational interviewing with patients who have schizophrenia and substance use disorders. Clin Psychol-Sci Pr 2007;14(1):58-63.

[62] Ryan RM, Patrick H, Deci EL, Williams GC. Facilitating health behaviour change and its maintenance: Interventions based on selfdetermination theory. Europ Health Psychol 2008;10:2-5.

[63] Ryan RM, Plant RW, O'Malley S. Initial motivations for alcohol treatment: Relations with patient characteristics, treatment involvement, and dropout. Addict Behav 1995;20(3):279-97.

[64] Zeldman A, Ryan RM, Fiscella K. Motivation, autonomy support, and entity beliefs: Their role in methadone maintenance treatment. J Soc Clin Psychol 2004;23(5):675-96.

[65] Ferron JC. Psychological mechanisms to treatment adherence among people with severe mental illness: Validating treatment motivation and working alliance measures. Diss Abstr Int 2007;68(11-A):4863.

[66] Wild T, Cunningham JA, Ryan RM. Social pressure, coercion, and client engagement at treatment entry: A self-determination theory perspective. Addict Behav 2006;31(10):1858-72.
[67] Kennedy K, Gregoire TK. Theories of motivation in addiction treatment: Testing the relationship of the transtheoretical model of change and self-determination theory. J Soc Work Pract Addict 2009;9(2):163-83.

[68] Zuroff DC, Koestner R, Moskowitz D, McBride C, Marshall M, Bagby M. Autonomous motivation for therapy: A new common factor in brief treatments for depression. Psychother Res 2007;17(2):137-47.

[69] Pelletier LG, Tuson KM, Haddad NK. Client motivation for therapy scale: A measure of intrinsic motivation, extrinsic motivation, and amotivation for therapy. J Pers Assess 1997;68(2):414 - 35 .

[70] Dwyer LA, Hornsey MJ, Smith LG, Oei TP, Dingle GA. Participant autonomy in cognitive behavioral group therapy: An integration of self-determination and cognitive behavioral theories. J Soc Clin Psychol 2011;30(1):24-46.

[71] DiClemente CC, Nidecker M, Bellack AS. Motivation and the stages of change among individuals with severe mental illness and substance abuse disorders. J Subst Abuse Treat 2008;34(1):25-35

[72] Ryan RM, Deci EL. A self-determination theory approach to psychotherapy: The motivational basis for effective change. Can Psychol 2008;49(3):186-93.

[73] Markland D, Ryan RM, Tobin VJ, Rollnick S. Motivational interviewing and self-determination theory. J Soc Clin Psychol 2005;24(6):811-31.

[74] Williams GC, Deci EL. Activating patients for smoking cessation throiugh physician autonomy support. Med Care 2001;39(8):81323.

[75] Williams GC, Gagné M, Ryan RM, Deci EL. Facilitating autonomous motivation for smoking cessation. Health Psychol 2002;21(1):40-50.

[76] Williams GC, Grow VM, Freedman ZR, Ryan RM, Deci EL. Motivational predictors of weight-loss and weight-loss maintenance. J Pers Soc Psychol 1996;70:115-26.

[77] Williams GC, McGregor HA, Zeldman A, Freedman ZR, Deci EL. Testing a self-determination theory process model for promoting glycemic control through diabetes self-management. Health Psychol 2004;23:58-66.

[78] Williams GC, Rodin GC, Ryan RM, Grolnick WS, Deci EL. Autonomous motivation and long-term medication adherence in adult outpatients. Health Psychol 1998; 17:269-76.

[79] Prochaska JO, Wright JA, Velicer WF. Evaluating theories of health behavior change: A hierarchy of criteria applied to the transtheoretical model. Appl Psychol 2008;57(4):561-88.

[80] Vansteenkiste M, Sierens E, Soenens B, Luyckx K, Lens W. Motivational profiles from a self-determination perspective: The quality of motivation matters. J Educ Psychol 2009;101(3):671-88.

[81] Ryan RM, Lynch MF, Vansteenkiste M, Deci EL. Motivation and autonomy in counseling, psychotherapy, and behavior change: A look at theory and practice. Couns Psychol 2010;39(2):193-260.

[82] Vansteenkiste M, Soenens B, Vandereycken W. Motivation to change in eating disorder patients: A conceptual clarification on the basis of self-determination theory. Int J Eat Disord 2005;37(3):20719.

[83] Abblett MR. Motivation for change in psychotherapy: The relationship between the transtheoretical model and selfdetermination theory and prediction of clinical services utilization. Diss Abstr Int 2002;63(4-B):2047.

[84] Mullan E, Markland D. Variations in self-determination across the stages of change for exercise in adults. Motiv Emot 1997;21(4):349-62.

[85] Lippke S, Ziegelmann JP. Theory-based health behavior change: Developing, testing, and applying theories for evidence-based interventions. Appl Psychol 2008;57(4):698-716. 